\title{
Longevity-associated mitochondrial DNA 5178 C/A polymorphism modulates the effects of coffee consumption on erythrocytic parameters in Japanese men: an exploratory cross-sectional analysis
}

Akatsuki Kokaze ${ }^{1 *}$, Mamoru Ishikawa ${ }^{2,3}$, Naomi Matsunaga², Kanae Karita², Masao Yoshida², Tadahiro Ohtsu', Hirotaka Ochiai ${ }^{1}$, Takako Shirasawa ${ }^{1}$, Hinako Nanri', Nobuyuki Saga' ${ }^{1}$, lichiro Ohtsu', Hiromi Hoshino ${ }^{1}$ and Yutaka Takashima

\begin{abstract}
Background: Mitochondrial DNA 5178 cytosine/adenine (Mt5178 C/A) polymorphism reportedly modulates the effects of coffee consumption on the risk of hypertension, dyslipidemia and abnormal glucose tolerance. The objective of this analysis was to investigate whether Mt5178 C/A polymorphism modifies the effects of coffee consumption on erythrocytic parameters in male Japanese health check-up examinees.
\end{abstract}

Methods: A total of 436 men (mean age \pm standard deviation, $54.1 \pm 7.8$ years) were selected from among individuals visiting the hospital for regular medical check-ups. After Mt5178 C/A genotyping, an exploratory cross-sectional analysis assessing the joint effects of Mt5178 C/A polymorphism and coffee consumption on red blood cell counts, hematocrit and hemoglobin was conducted.

Results: For Mt5178C genotypic men, after adjustment for age, body mass index, alcohol consumption, habitual smoking and green tea consumption, coffee consumption significantly decreased red blood cell counts ( $P$ for trend $=0.022$ ) and hemoglobin ( $P$ for trend $=0.035$ ). The risk of anemia, defined as hemoglobin of $<14 \mathrm{~g} / \mathrm{dL}$, after the aforementioned adjustment, appeared to depend on coffee consumption ( $P$ for trend $=0.078$ ), and the adjusted odds ratio for anemia was significantly higher in men who consumed $\geq 4$ cups of coffee per day than in those who consumed $<1$ cup per day (odds ratio $=3.771,95 \%$ confidence interval: 1.088 to $13.06, P=0.036$ ). For Mt5178A genotypic men, coffee consumption possibly reduced the risk of anemia ( $P$ for trend $=0.049$ ). However, after the aforementioned adjustment, the statistical significance disappeared ( $P$ for trend $=0.137$ ).

Conclusions: This exploratory cross-sectional analysis suggests that Mt5178 C/A polymorphism modulates the effects of coffee consumption on erythrocytic parameters and the risk of anemia in male Japanese health check-up examinees.

Keywords: Anemia, Coffee consumption, Hemoglobin, Mitochondrial DNA polymorphism, Personalized preventive medicine, Red blood cell

\footnotetext{
* Correspondence: akokaze@med.showa-u.ac.jp

${ }^{1}$ Department of Public Health, Showa University School of Medicine, 1-5-8

Hatanodai, Shinagawa-ku, Tokyo 142-8555, Japan

Full list of author information is available at the end of the article
} 


\section{Background}

Studying culturally diverse populations increases the potential of revealing gene-environment interactions [1]. Personalized medicine utilizes gene-environment interactions for the prevention, diagnosis and treatment of diseases [2]. From the viewpoint of prevention, information on gene-environment interactions is necessary to determine the individualized optimum for maximizing the risk reduction and minimizing the risk increase of behavior for lifestyle-related diseases.

Mitochondrial DNA sequences are utilized in studies of the history and evolution of human populations [3]. In physiological anthropology, Nishimura et al. reported the interaction between mitochondrial DNA haplogroups and seasonal cold acclimatization [4]. Mitochondrial DNA cytosine/adenine (Mt5178 C/A) polymorphism, also known as NADH dehydrogenase subunit-2 237 leucine/methionine (ND2-237 Leu/Met) polymorphism, is associated with longevity in the Japanese population [5]. The frequency of the Mt5178A genotype is significantly higher in Japanese centenarians than in the general population [5]. Japanese individuals with Mt5178A are more resistant to hypertension [6], diabetes [7], myocardial infarction $[8,9]$ and cerebrovascular disorders [10] than those with Mt5178C. Moreover, Mt5178 C/A polymorphism interacts with several lifestyle habits, namely habitual smoking [11-14], alcohol consumption [6,14,15], coffee consumption [16-18] and green tea consumption [19], on the risk of lifestyle-related diseases. Mt5178 C/A polymorphism influences the effects of coffee consumption on the risk of hypertension [16], hyper-low-density lipoprotein (LDL) cholesterolemia [17] and the clustering of cardiovascular risk factors [18].

Although coffee intake appears to be a beneficial lifestyle behavior for health $[20,21]$, several researchers have reported that coffee consumption is associated with anemia [22-24], and this has been the focus of bioarchaeological studies $[25,26]$. Mitochondria play many crucial roles in hematopoietic cell homeostasis [27]. We have previously reported the joint effects of Mt5178 C/A polymorphism and cigarette smoking on erythrocytic parameters [11]. However, there have been no studies on the gene-environment interaction between Mt5178 C/A polymorphism and coffee consumption on erythrocytic parameters.

The objective of this study was to investigate whether there is a combined effect of longevity-associated Mt5178 C/A polymorphism and coffee consumption on erythrocytic parameters in male Japanese health check-up examinees.

\section{Methods}

Participants

Participants were recruited from among individuals visiting the Mito Red Cross Hospital for regular medical check-ups between August 1999 and August 2000. This study was conducted in accordance with the Declaration of Helsinki and was approved by the Ethics Committee of the Kyorin University School of Medicine. Written informed consent was obtained from 602 volunteers before participation. Because the number of women was insufficient for classification into groups based on Mt5178 C/A genotype and coffee consumption, female health check-up examinees were excluded. Male health check-up examinees with unclear data were also excluded. Therefore, the subjects of this analysis comprised 436 Japanese men (mean age \pm SD, $54.1 \pm 7.8$ years).

\section{Clinical characteristics of participants}

Hematological parameters, determined using an automated counter (Sysmex SE9000; Sysmex, Kobe, Japan), were obtained from the results of regular medical checkups. Anemia was defined as hemoglobin of $<14 \mathrm{~g} / \mathrm{dL}$ [28]. Body mass index (BMI) was defined as the ratio of the individual's weight $(\mathrm{kg})$ to the square of their height $(\mathrm{m})$. A survey of coffee intake, habitual smoking, alcohol consumption and green tea intake was performed using a questionnaire. As in previous reports $[17,18]$, coffee consumption was categorized based on the number of cups of coffee per day ( $<1$ cup per day, 1 to 3 cups per day, $\geq 4$ cups per day). Habitual smoking was classified as non- or ex-smokers and current smokers. Alcohol consumption was classified based on drinking frequency (daily drinkers; occasional drinkers, which included those who drink several times per week or per month; and non- or exdrinkers). Green tea consumption was classified based on the number of cups of green tea per day $(<1$ cup per day, 1 to 4 cups per day, $\geq 5$ cups per day).

\section{Genotyping}

DNA was extracted from white blood cells using a DNA Extractor WB kit (Wako Pure Chemical Industries, Osaka, Japan). Mt5178 C/A polymorphism was detected by polymerase chain reaction (PCR) and digestion with AluI restriction enzyme. The sequence of primers was: forward 5'-CTTAGCATACTCCTCAATTACCC-3' and reverse 5'-GTGAATTCTTCGATAATGGCCCA-3'. PCR was performed with $50 \mathrm{ng}$ genomic DNA in a buffer containing $0.2 \mu \mathrm{mol} / \mathrm{L}$ of each primer, $1.25 \mathrm{mmol} / \mathrm{L}$ deoxyribonucleotide triphosphates, $1.5 \mathrm{mmol} / \mathrm{L} \mathrm{MgCl}_{2}$ and $1 \mathrm{U}$ of Taq DNA polymerase. After initial denaturation at $94^{\circ} \mathrm{C}$ for $5 \mathrm{~min}$, PCR was conducted for 40 cycles in the following steps: denaturation at $94^{\circ} \mathrm{C}$ for $30 \mathrm{~s}$, annealing at $60^{\circ} \mathrm{C}$ for $60 \mathrm{~s}$ and polymerase extension at $72^{\circ} \mathrm{C}$ for $90 \mathrm{~s}$. After cycling, a final extension at $72^{\circ} \mathrm{C}$ for 10 min was performed. PCR products were digested with $A l u \mathrm{I}$ restriction enzyme (Nippon Gene, Tokyo, Japan) at $37^{\circ} \mathrm{C}$ overnight, and were electrophoresed in 1.5\% agarose gels stained with ethidium bromide for visualization under ultraviolet 
light. The absence of an AluI site was designated as $\mathrm{Mt} 5178 \mathrm{~A}$, and the presence of this restriction site was designated as Mt5178C.

\section{Statistical analyses}

Statistical analyses were performed using SAS statistical software version 9.2 for Windows (SAS Institute, Inc., Cary, NC, USA). Multiple logistic regression analysis was used to calculate odds ratios (ORs) for the risk of anemia (hemoglobin $<14 \mathrm{~g} / \mathrm{dL}$ ). For multiple logistic regression analysis and analysis of covariance, habitual smoking (non- or ex-smokers $=0$, current smokers $=1$ ), alcohol consumption (non- or ex-drinkers $=0$, occasional drinkers, including those who drink several times per week or per month $=1$, daily drinkers $=2$ ) and green tea consumption ( $<1$ cup per day $=1,1$ to 3 cups per day $=2, \geq 5$ cups per day $=3$ ) were numerically coded. Differences with $P$ values of less than 0.05 were considered to be statistically significant.

\section{Results}

In our study population, the frequency of Mt5178C was 41.0\% and that of Mt5178A genotype was 39.0\% (Table 1). No significant differences in erythrocytic parameters, namely red blood cell (RBC) count, hematocrit, hemoglobin, mean corpuscular volume, mean corpuscular hemoglobin or mean corpuscular hemoglobin concentration, were observed between the Mt5178C and Mt5178A genotypes. However, white blood cell count was significantly higher in Mt5178A genotypic men than in Mt5178C genotypic men $(P=0.026)$.
Bonferroni correction for multiple comparisons revealed no statistically significant differences in erythrocytic parameters among the three coffee consumption groups ( $<1$ cup per day, 1 to 3 cups per day and $\geq 4$ cups per day) by Mt5178 C/A genotype (Table 2). However, after adjusting for age, BMI, alcohol consumption, habitual smoking and green tea consumption, a significant negative association between coffee consumption and RBC count was seen in participants with Mt5178C ( $P$ for trend $=$ 0.022). After the aforementioned adjustment, RBC count was significantly lower in those who consumed $\geq 4$ cups of coffee per day than in those who consumed $<1$ cup of coffee per day $(P=0.031)$. The aforementioned adjustment also revealed a significant negative association between coffee consumption and hemoglobin in participants with $\mathrm{Mt5178C}$ ( $P$ for trend $=0.035$ ). A negative trend between coffee consumption and hematocrit was also observed in participants with Mt5178C, although this did not reach significance $(P$ for trend $=0.059)$. No significant relationships between coffee consumption and erythrocytic parameters were observed in participants with Mt5178A.

No significant relationships between coffee consumption and risk of anemia were observed in Mt5178C genotypic men (Table 3). Although not significant, after adjustment for age, BMI, alcohol consumption, habitual smoking and green tea consumption, the risk of anemia may be related to coffee consumption ( $P$ for trend $=$ 0.078). The adjusted OR for anemia was significantly higher in participants with Mt5178C who consumed $\geq 4$ cups of coffee per day than in those who consumed $<1$

Table 1 Hematological parameters of study participants by Mt5178 C/A genotype

\begin{tabular}{|c|c|c|c|}
\hline & $\begin{array}{l}\text { Mt5178C } \\
N=266\end{array}$ & $\begin{array}{l}\text { Mt5178A } \\
N=170\end{array}$ & $P$ value \\
\hline Age $(y)^{a}$ & $54.5 \pm 7.7$ & $53.6 \pm 7.8$ & 0.243 \\
\hline Body mass index $\left(\mathrm{kg} / \mathrm{m}^{2}\right)^{a}$ & $23.2 \pm 2.8$ & $23.5 \pm 2.6$ & 0.163 \\
\hline Red blood cell count $\left(10^{4} / \mu \mathrm{L}\right)^{\mathrm{a}}$ & $480 \pm 37$ & $487 \pm 41$ & 0.066 \\
\hline Hematocrit $(\%)^{a}$ & $43.8 \pm 3.0$ & $44.3 \pm 2.8$ & 0.092 \\
\hline Hemoglobin $(g / d L)^{a}$ & $15.0 \pm 1.2$ & $15.1 \pm 1.0$ & 0.199 \\
\hline Mean corpuscular volume $(\mathrm{fl})^{\mathrm{a}}$ & $91.4 \pm 4.3$ & $91.2 \pm 4.6$ & 0.644 \\
\hline Mean corpuscular hemoglobin $(p g)^{a}$ & $31.2 \pm 1.7$ & $31.1 \pm 1.7$ & 0.487 \\
\hline Mean corpuscular hemoglobin concentration $(\mathrm{g} / \mathrm{dL})^{a}$ & $34.2 \pm 0.8$ & $34.1 \pm 0.8$ & 0.529 \\
\hline White blood cell count $\left(10^{2} / \mu \mathrm{L}\right)^{\mathrm{b}}$ & $56.8 \pm 14.6$ & $60.5 \pm 18.3$ & 0.026 \\
\hline Platelet count $\left(10^{4} / \mu \mathrm{L}\right)^{a}$ & $22.1 \pm 4.8$ & $22.6 \pm 5.3$ & 0.322 \\
\hline Coffee consumption ( $<1$ cup per day/1 to 3 cups per day/ $\geq 4$ cups per day) $(\%)^{c}$ & $44.8 / 46.2 / 9.0$ & $36.5 / 51.2 / 12.3$ & 0.188 \\
\hline Current smokers $(\%)^{c}$ & 42.1 & 41.8 & 0.944 \\
\hline Alcohol consumption (non- or ex-/occasionally/daily) (\%) & 18.4/35.0/46.6 & 12.9/40.0/47.1 & 0.269 \\
\hline Green tea consumption ( $<1$ cup per day/ 1 to 4 cups per day $/ \geq 5$ cups per day) $(\%)^{c}$ & 22.6/41.3/36.1 & 20.0/45.3/34.7 & 0.689 \\
\hline
\end{tabular}

Age, body mass index, red blood cell counts, hematocrit, hemoglobin, mean corpuscular volume, mean corpuscular hemoglobin, mean corpuscular hemoglobin concentration, white blood cell counts, and platelet counts are given as means \pm SD. All $P$ values depict significance of differences between Mt5178C and Mt5178A. ${ }^{a}$ Student's t-test, ${ }^{b}$ Welch's t-test, ${ }^{C}$ chi-squared test. 
Table 2 Erythrocytic parameters by coffee consumption status and Mt5178 C/A genotype

\begin{tabular}{|c|c|c|c|c|}
\hline & \multicolumn{3}{|c|}{ Coffee consumption } & \multirow[t]{2}{*}{$P$ for trend } \\
\hline & $<1$ cup per day & 1 to 3 cups per day & $\geq 4$ cups per day & \\
\hline Mt5178C & $N=119$ & $N=123$ & $N=24$ & \\
\hline Red blood cell count $\left(10^{4} / \mu \mathrm{L}\right)$ & $480 \pm 3$ & $481 \pm 3$ & $468 \pm 8$ & 0.349 \\
\hline Red blood cell count $\left(10^{4} / \mu \mathrm{L}\right)^{\mathrm{a}}$ & $484 \pm 3$ & $480 \pm 3$ & $463 \pm 7^{*}$ & 0.022 \\
\hline Hematocrit (\%) & $43.9 \pm 0.3$ & $43.8 \pm 0.3$ & $43.1 \pm 0.6$ & 0.426 \\
\hline Hematocrit (\%) & $43.9 \pm 0.3$ & $43.5 \pm 0.3$ & $42.6 \pm 0.6$ & 0.059 \\
\hline Hemoglobin (g/dL) & $15.0 \pm 0.1$ & $14.9 \pm 0.1$ & $14.8 \pm 0.2$ & 0.329 \\
\hline Hemoglobin $(\mathrm{g} / \mathrm{dL})^{\mathrm{a}}$ & $15.0 \pm 0.1$ & $14.8 \pm 0.1$ & $14.6 \pm 0.2$ & 0.035 \\
\hline Mean corpuscular volume (fl) & $91.4 \pm 0.4$ & $91.2 \pm 0.4$ & $92.2 \pm 0.9$ & 0.681 \\
\hline Mean corpuscular volume $(\mathrm{fl})^{\mathrm{a}}$ & $90.8 \pm 0.4$ & $90.9 \pm 0.4$ & $92.1 \pm 0.8$ & 0.275 \\
\hline Mt5178A & $N=62$ & $N=87$ & $N=21$ & \\
\hline Red blood cell count $\left(10^{4} / \mu \mathrm{L}\right)$ & $490 \pm 5$ & $485 \pm 4$ & $487 \pm 9$ & 0.615 \\
\hline Red blood cell count $\left(10^{4} / \mu \mathrm{L}\right)^{\mathrm{a}}$ & $491 \pm 5$ & $483 \pm 5$ & $487 \pm 9$ & 0.485 \\
\hline Hematocrit (\%) & $44.2 \pm 0.4$ & $44.2 \pm 0.3$ & $44.6 \pm 0.6$ & 0.668 \\
\hline Hematocrit (\%) ${ }^{\mathrm{a}}$ & $44.4 \pm 0.4$ & $44.1 \pm 0.3$ & $44.4 \pm 0.6$ & 0.889 \\
\hline Hemoglobin (g/dL) & $15.1 \pm 0.1$ & $15.1 \pm 0.1$ & $15.2 \pm 0.2$ & 0.758 \\
\hline Hemoglobin $(\mathrm{g} / \mathrm{dL})^{\mathrm{a}}$ & $15.2 \pm 0.1$ & $15.0 \pm 0.1$ & $15.1 \pm 0.2$ & 0.711 \\
\hline Mean corpuscular volume (fl) & $90.6 \pm 0.6$ & $91.5 \pm 0.5$ & $91.7 \pm 1.0$ & 0.247 \\
\hline Mean corpuscular volume (fl) ${ }^{\mathrm{a}}$ & $90.8 \pm 0.6$ & $91.5 \pm 0.5$ & $91.4 \pm 0.9$ & 0.451 \\
\hline
\end{tabular}

${ }^{\mathrm{a}}$ Mean \pm standard error adjusted for age, body mass index, alcohol consumption, habitual smoking and green tea consumption. Bonferroni correction for multiple comparison was applied. ${ }^{*} P<0.05$ versus $<1$ cup of coffee per day.

cup per day (adjusted OR $=3.771$, 95\% confidence interval: 1.088 to $13.06, P=0.036)$. In Mt5178A genotypic men, a significant negative association between coffee consumption and the risk of anemia was observed $(P$ for trend $=0.049)$. However, after the aforementioned adjustment, statistical significance disappeared $(P$ for trend $=0.137)$.

\section{Discussion}

In the present study, the combined effects of Mt5178 $\mathrm{C} / \mathrm{A}$ polymorphism and coffee consumption on erythrocytic parameters or the risk of anemia was observed in male Japanese health check-up examinees. An inverse association between coffee consumption and erythrocytic parameters, namely RBC count and hemoglobin, was

Table 3 Odds ratios and $95 \%$ confidence intervals for anemia (hemoglobin <14 g/dL) by Mt5178 C/A genotype and coffee consumption

\begin{tabular}{|c|c|c|c|c|}
\hline \multirow{2}{*}{$\begin{array}{l}\text { Genotype and } \\
\text { coffee consumption }\end{array}$} & \multicolumn{2}{|l|}{ Frequency (\%) } & \multirow{2}{*}{$\begin{array}{l}\text { Odds ratio ( } 95 \% \\
\text { confidence interval) }\end{array}$} & \multirow{2}{*}{$\begin{array}{l}\text { Adjusted odds ratio } \\
\text { ( } 95 \% \text { confidence interval) }\end{array}$} \\
\hline & $\begin{array}{l}\text { Normal hemoglobin level } \\
\text { (hemoglobin } \geq 14 \mathrm{~g} / \mathrm{dL} \text { ) }\end{array}$ & $\begin{array}{l}\text { Anemia } \\
\text { (hemoglobin <14 g/dL) }\end{array}$ & & \\
\hline \multicolumn{5}{|l|}{$\mathrm{Mt5178C}$} \\
\hline$<1$ cup per day & $99(83.2)$ & $20(16.8)$ & 1 (reference) & 1 (reference) \\
\hline 1 to 3 cups per day & $104(84.6)$ & 19 (15.4) & $0.904(0.456$ to 1.795$)$ & 1.140 (0.527 to 2.467$)$ \\
\hline \multirow[t]{2}{*}{$\geq 4$ cups per day } & $17(70.8)$ & $7(29.2)$ & $2.038(0.748$ to 5.556$)$ & $3.771(1.088 \text { to } 13.06)^{*}$ \\
\hline & & & $P$ for trend $=0.386$ & $P$ for trend $=0.078$ \\
\hline \multicolumn{5}{|l|}{ Mt5178A } \\
\hline$<1$ cup per day & $51(82.3)$ & $11(17.7)$ & 1 (reference) & 1 (reference) \\
\hline 1 to 3 cups per day & $80(92.0)$ & $7(8.0)$ & 0.406 (0.148 to 1.115$)$ & 0.383 (0.118 to 1.249$)$ \\
\hline \multirow[t]{2}{*}{$\geq 4$ cups per day } & $20(95.2)$ & $1(4.8)$ & $0.232(0.028$ to 1.915$)$ & 0.301 (0.029 to 3.094) \\
\hline & & & $P$ for trend $=0.049$ & $P$ for trend $=0.137$ \\
\hline
\end{tabular}

${ }^{a}$ Odds ratio adjusted for age, body mass index, habitual alcohol consumption, habitual smoking and green tea consumption. ${ }^{*} P<0.05$. 
observed in participants with Mt5178C. The risk of anemia was significantly higher in those who consumed $\geq 4$ cups of coffee per day than in those who consumed $<1$ cup per day. In participants with Mt5178A, coffee consumption did not appear to influence erythrocytic parameters, but may reduce the risk of anemia.

Although Mt5178C genotype is reported to be overwhelmingly predominant worldwide [29], genetic epidemiological research has reported that the frequency of Mt5178A is $42.1 \%$ in the community-dwelling Japanese population [30]. A chi-squared test did not reveal a significant difference between the frequency of Mt5178A in this study and in community-based molecular epidemiological surveys [30], thus suggesting that there is no genetic bias in the participants in this study.

Maternal coffee intake is reportedly a risk factor of both maternal [22,23] and infant [22] iron deficiency anemia. Coffee consumption is also reported to be one of the risk factors for iron deficiency anemia in preschool children [24]. $\mathrm{Fe}^{55}$ and $\mathrm{Fe}^{59}$ isotope studies have demonstrated the inhibitory effects of coffee on non-heme iron absorption in human subjects [31]. However, no significant effects of discontinuing coffee consumption on changes in hemoglobin, hematocrit or plasma iron in either non-anemic or anemic children were observed in a randomized intervention study [32]. Moreover, an inverse relationship between coffee consumption and risk of anemia was observed in a large-scale cross-sectional study [33]. Considering these results, the addition of genetic information may contribute to future clinical or epidemiological studies with regard to the effects of coffee consumption on the risk of anemia or iron absorption.

Previous cross-sectional studies reported the joint effects of Mt5178 C/A polymorphism and coffee consumption on the risk of hypertension [16], risk of hyperLDL cholesterolemia [17] and clustering of cardiovascular risk factors [18]. Amongst men with Mt5178C genotype, the risk of hypertension was significantly lower in those who consumed $\geq 2$ cups of coffee per day than in those who consumed $\leq 1$ cup of coffee per day [16]. The risk of the clustering of cardiovascular risk factors was significantly lower in those who consumed $\geq 1$ cup of coffee per day than in those who consumed $<1$ cup of coffee per day [18]. Amongst Mt5178A genotypic men, the risk of hyperLDL cholesterolemia was significantly higher in those who consumed $\geq 1$ cup of coffee per day than in those who consumed $<1$ cup of coffee per day [17]. Taken together, the present results do not suggest that coffee intake is more beneficial for health in men with Mt5178C than in those with Mt5178A.

Because the success of candidate gene analysis depends on the choice of genes studied, the candidate gene approach alone is generally thought to be insufficient in the study of disease susceptibility or physiological function
[34]. Moreover, our research focused on only one mitochondrial DNA polymorphism. Therefore, the biological mechanisms of the combined effects of Mt5178 C/A polymorphism and coffee consumption on erythrocytic parameters remain unknown. However, they probably depend on the biochemical differences in response to some compounds in coffee between ND2-237Leu and ND2-237Met. NADH dehydrogenase is recognized as the major physiological and pathological site of reactive oxygen species (ROS) generation in mitochondria, and itself as a target of assault by ROS [35]. Extrapolation from animal models [36,37] to humans would suggest that ND2-237Met suppresses ROS production and/or protects NADH dehydrogenase itself from ROS. Coffee intake exerts antioxidant potentials in human subjects [38]. Our previous studies showed that coffee consumption exerts antioxidant behaviors in men with ND2237Leu rather than in those with ND2-237Met [16-18]. However, it remains uncertain why coffee consumption does not exert antioxidant effects on hematopoiesis in ND2-237Leu genotypic men. Other biochemical effects may play a crucial role in the joint effects of ND2237Leu/Met polymorphism and coffee consumption on erythrocytic parameters. In any case, elucidating the mechanisms of the joint effects of ND2-237 Leu/Met polymorphism and coffee consumption on erythroid lineage remains a matter for further pathophysiological investigation.

Although the World Health Organization defines the lower limit for normal hemoglobin levels to be $13 \mathrm{~g} / \mathrm{dL}$ in men [28], many epidemiological studies have adopted hemoglobin levels of $14 \mathrm{~g} / \mathrm{dL}$ as the lower limit in men [28]. Therefore, anemia was defined as hemoglobin of $<14 \mathrm{~g} / \mathrm{dL}$ in this study. There are many different types of anemia, for example, aplastic anemia, hemolysis, hemorrhage, iron deficiency anemia, sideroblastic anemia and megaloblastic anemia [28]. However, this crosssectional study did not classify the anemia. Diagnostic approaches to anemia will therefore be required to investigate the joint effects of Mt5178 C/A polymorphism and coffee consumption on the risk of anemia.

As noted above, this study investigated only one mitochondrial DNA polymorphism. Large deletions in mitochondrial DNA are reportedly a hallmark of Pearson's syndrome, a rare congenital disorder with sideroblastic anemia [27]. Cui et al. reported that mitochondrial DNA mutations were associated with aplastic anemia [39]. They found that mutation rates were particularly high in the ND2 coding region in the mitochondrial DNA genomes of patients with aplastic anemia. Mitochondrial genome mutations occasionally result in mitochondrial dysfunctions. Therefore, information on other polymorphisms, mutations or deletions in mitochondrial DNA will be necessary. Moreover, information 
on causative chromosomal mutations for anemia [28] is also required.

In addition to the lack of anemia classification and information on other mitochondrial DNA genotypes or chromosomal mutations, there are several crucial limitations in this study. First, the study sample was very small. The exploratory nature of study did not allow estimation of sample size in advance. However, post-hoc power analyses for multiple logistic regression analysis, utilizing G*Power 3 [40], indicated that this study was not underpowered. Second, participants comprised only men. Third, we analyzed only a single population; to avoid errors in molecular epidemiological studies, it is necessary to analyze two or more independent data sets. Fourth, this study was a cross-sectional study, and although the study design is able to suggest causal links, it cannot establish valid causality. To overcome these limitations, a prospective cohort study in a larger study sample, including multiple populations, is necessary. Fifth, the evaluation of habitual coffee consumption was based on the number of cups consumed per day. Whether there is any interaction between Mt5178 C/A polymorphism and volume of chlorogenic acids, caffeine or other compounds in coffee on erythrocytic parameters or the risk of anemia warrants further investigation.

\section{Conclusions}

This exploratory cross-sectional study suggests that Mt5178 C/A polymorphism influences the effects of coffee consumption on erythrocytic parameters in male Japanese health check-up examinees. To the best of our knowledge, this is a novel gene-environment interaction on RBC count, hemoglobin and risk of anemia. Although coffee intake is recommended for Mt5178C genotypic men to reduce the risk of atherosclerotic diseases $[16,18]$, abstaining from coffee intake may be recommended to reduce the risk of anemia. For Mt5178A genotypic men, coffee consumption may prevent anemia. This gene-environment interaction may contribute to both individualized prevention for anemia and cardiovascular diseases, and elucidation of the pathophysiological relationship among mitochondria, coffee consumption and hematopoiesis. Moreover, the study of gene-environment interactions across heterogeneous groups with various lifestyles [1] may provide anthropological insights.

\footnotetext{
Abbreviations

BMl: body mass index; Mt5178 C/A: mitochondrial DNA 5178 cytosine/ adenosine; LDL: low-density lipoprotein; ND2-237 Leu/Met: NADH dehydrogenase subunit-2 237 leucine/methionine; OR: odds ratio; PCR: polymerase chain reaction; $\mathrm{RBC}$ : red blood cell; $\mathrm{ROS}$ : reactive oxygen species.
}

\section{Competing interests}

The authors declare that they have no competing interests.

\section{Authors' contributions}

AK designed the study, performed the epidemiological survey, carried out genotyping, analyzed the data, and drafted the manuscript; $\mathrm{Ml}$ collected the samples; MY and KK performed the epidemiological survey; NM assisted with genotyping; TO, HO, TS, HN, NS, $\mathrm{IO}$ and $\mathrm{HH}$ assisted with data analysis and helped with interpreting the results; YT designed the study and performed the epidemiological survey. All authors have read and approved the final manuscript.

\section{Acknowledgements}

This study was supported in part by Grants-in-Aid from the Ministry of Education, Culture, Sports, Science and Technology of Japan (No. 14570355, No. 18590572, No. 23500859 and No. 26350908) and the Chiyoda Mutual Life Foundation.

\section{Author details}

'Department of Public Health, Showa University School of Medicine, 1-5-8 Hatanodai, Shinagawa-ku, Tokyo 142-8555, Japan. ${ }^{2}$ Department of Public Health, Kyorin University School of Medicine, 6-20-2 Shinkawa, Mitaka-shi, Tokyo 181-8611, Japan. ${ }^{3}$ Mito Red Cross Hospital, 3-12-48 Sannomaru, Mito-shi, Ibaraki 310-0011, Japan.

Received: 18 June 2014 Accepted: 27 November 2014

Published: 20 December 2014

\section{References}

1. Anand SS: The value of studying gene-environment interactions in culturally diverse populations. Can J Physiol Pharmacol 2005, 83:42-46.

2. Offit K: Personalized medicine: new genomics, old lessons. Hum Genet 2011, 130:3-14.

3. Pakendorf B, Stoneking M: Mitochondrial DNA and human evolution Annu Rev Genomics Hum Genet 2005, 6:165-183.

4. Nishimura T, Motoi M, Niri Y, Hoshi Y, Kondo R, Watanuki S: Relationship between seasonal cold acclimatization and mtDNA haplogroup in Japanese. J Physiol Anthropol 2012, 31:22.

5. Tanaka M, Gong JS, Zhang J, Yoneda M, Yagi K: Mitochondrial genotype associated with longevity. Lancet 1998, 351:185-186.

6. Kokaze A, Ishikawa M, Matsunaga N, Yoshida M, Satoh M, Teruya K, Masuda Y, Honmyo R, Uchida Y, Takashima Y: NADH dehydrogenase subunit-2 237 Leu/Met polymorphism modifies the effects of alcohol consumption on risk for hypertension in middle-aged Japanese men. Hypertens Res 2007, 30:213-218

7. Wang D, Taniyama M, Suzuki Y, Katagiri T, Ban Y: Association of the mitochondrial DNA $5178 \mathrm{~A} / \mathrm{C}$ polymorphism with maternal inheritance and onset of type 2 diabetes in Japanese patients. Exp Clin Endocrinol Diabetes 2001, 109:361-364

8. Mukae S, Aoki S, Itoh S, Sato R, Nishio K, Iwata T, Katagiri T: Mitochondrial $5178 \mathrm{~A} / \mathrm{C}$ genotype is associated with acute myocardial infarction. Circ J 2003, 67:16-20

9. Takagi K, Yamada Y, Gong JS, Sone T, Yokota M, Tanaka M: Association of a $5178 \mathrm{C} \rightarrow \mathrm{A}$ (Leu237Met) polymorphism in the mitochondrial DNA with a low prevalence of myocardial infarction in Japanese individuals. Atherosclerosis 2004, 175:281-286

10. Ohkubo R, Nakagawa M, Ikeda K, Kodama T, Arimura K, Akiba S, Saito M, Ookatsu Y, Atsuchi Y, Yamano Y, Osame M: Cerebrovascular disorders and genetic polymorphisms: mitochondrial DNA5178C is predominant in cerebrovascular disorders. J Neurol Sci 2002, 198:31-35.

11. Kokaze A, Ishikawa M, Matsunaga N, Yoshida M, Makita R, Satoh M, Teruya K, Sekiguchi K, Masuda Y, Harada M, Uchida Y, Takashima Y: Interaction between longevity-associated mitochondrial DNA 5178 C/A polymorphism and cigarette smoking on hematological parameters in Japanese men. Arch Gerontol Geriatr 2005, 40:113-122.

12. Kokaze A, Ishikawa M, Matsunaga N, Yoshida M, Satoh M, Teruya K Honmyo R, Shirasawa T, Hoshino H, Takashima Y: Longevity-associated mitochondrial DNA $5178 \mathrm{C} / \mathrm{A}$ polymorphism and its interaction with cigarette consumption are associated with pulmonary function in middle-aged Japanese men. J Hum Genet 2007, 52:680-685.

13. Kokaze A, Ishikawa M, Matsunaga N, Karita K, Yoshida M, Shimada N, Ohtsu T, Shirasawa T, Ochiai H, Satoh M, Hashimoto M, Hoshino H, Takashima Y Mitochondrial DNA $5178 \mathrm{C} / \mathrm{A}$ polymorphism influences the effects of 
habitual smoking on the risk of dyslipidemia in middle-aged Japanese men. Lipids Health Dis 2012, 11:97.

14. Kokaze A, Ishikawa M, Matsunaga N, Karita K, Yoshida M, Ohtsu T, Ochiai H, Shirasawa T, Nanri H, Hoshino H, Takashima Y: Difference in effects of cigarette smoking or alcohol consumption on serum non-high-density lipoprotein cholesterol levels is related to mitochondrial DNA $5178 \mathrm{C} / \mathrm{A}$ polymorphism in middle-aged Japanese men: a cross-sectional study. J Physiol Anthropol 2014, 33:1.

15. Kokaze A, Ishikawa M, Matsunaga N, Karita K, Yoshida M, Shimada N, Ohtsu T, Shirasawa T, Ochiai H, Hoshino H, Takashima Y: Combined effect of mitochondrial DNA $5178 \mathrm{C} / \mathrm{A}$ polymorphism and alcoho consumption on estimated glomerular filtration rate in male Japanese health check-up examinees: a cross-sectional study. BMC Nephrol 2013 14:35.

16. Kokaze A, Ishikawa M, Matsunaga N, Karita K, Yoshida M, Ohtsu T, Shirasawa T, Sekii H, Ito T, Kawamoto T, Takashima Y: NADH dehydrogenase subunit-2 237 Leu/Met polymorphism modulates the effects of coffee consumption on the risk of hypertension in middleaged Japanese men. J Epidemiol 2009, 19:231-236.

17. Kokaze A, Ishikawa M, Matsunaga N, Karita K, Yoshida M, Shimada N, Ohtsu T, Shirasawa T, Ochiai H, Kawamoto T, Ito T, Hoshino H, Takashima Y: Combined effect of longevity-associated mitochondrial DNA 5178 C/A polymorphism and coffee consumption on the risk of hyper-LDL cholesterolemia in middle-aged Japanese men. J Hum Genet 2010 55:577-581.

18. Ito T, Kokaze A, Ishikawa M, Matsunaga N, Karita K, Yoshida M, Ohtsu T, Ochiai $\mathrm{H}$, Shirasawa T, Nanri H, Hoshino H, Takashima Y: Joint effects of mitochondrial DNA $5178 \mathrm{C} / \mathrm{A}$ polymorphism and coffee consumption or alcohol consumption on clustering of cardiovascular risk factors in middle-aged Japanese men: a cross-sectional study. J Diab Metab Disord 2014, 13:4.

19. Kokaze A, Ishikawa M, Matsunaga N, Karita K, Yoshida M, Ohtsu T, Ochiai $H$ Shirasawa T, Nanri H, Hoshino H, Takashima Y: Unexpected combined effects of NADH dehydrogenase subunit-2 237 Leu/Met polymorphism and green tea consumption on renal function in male Japanese health check-up examinees: a cross-sectional study. J Negat Results Biomed 2013, 12:17.

20. Cano-Marquina A, Tarin JJ, Cano A: The impact of coffee on health. Maturitas 2013, 75:7-21.

21. Cornelis MC: Coffee intake. Prog Mol Biol Trans/ Sci 2012, 108:293-322.

22. Muñoz LM, Lönnerdal B, Keen CL, Dewey KG: Coffee consumption as a factor in iron deficiency anemia among pregnant women and their infants in Costa Rica. Am J Clin Nutr 1988, 48:645-651.

23. Ahmed F, Al-Sumale MA: Risk factors associated with anemia and iron deficiency among Kuwaiti pregnant women. Int J Food Sci Nutr 2011, 62:585-592.

24. Adish AA, Esrey SA, Gyorkos TW, Johns T: Risk factors for iron deficiency anemia in preschool children in northern Ethiopia. Public Health Nutr 1999, 2:243-252.

25. Sullivan A: Prevalence and etiology of acquired anemia in Medieval York, England. Am J Phys Anthropol 2005, 128:252-272.

26. Walker PL, Bathurst RR, Richman R, Gjerdrum T, Andrushko VA: The causes of porotic hyperostosis and cribra orbitalia: a reappraisal of the irondeficiency-anemia hypothesis. Am J Phys Anthropol 2009, 139:109-125.

27. Fontenay $\mathrm{M}$, Cathelin S, Amiot M, Gyan E, Solary E: Mitochondria in hematopoiesis and hematological diseases. Oncogene 2006, 25:4757-4767

28. Means RT Jr, Glader B: Anemia: General considerations. In Wintrobe's Clinical Hematology. 12th edition. Edited by Greer JP, Foerster J, Rodgers GM, Paraskevas F, Glader B, Arber DA, Means RT Jr. Philadelphia: Lippincott Williams \& Wilkins; 2009:779-809.

29. Cann RL, Stoneking M, Wilson AC: Mitochondrial DNA and human evolution. Nature 1987, 325:31-36.

30. Shimokata H, Yamada Y, Nakagawa M, Okubo R, Saido T, Funakoshi A Miyasaka K, Ohta S, Tsujimoto G, Tanaka M, Ando F, Niino N: Distribution of geriatric disease-related genotypes in the national institute for longevity sciences, longevity study of aging (NILS-LSA). J Epidemiol 2000, 10:S46-S55.

31. Morck TA, Lynch SR, Cook JD: Inhibition of food iron absorption by coffee. Am J Clin Nutr 1983, 37:416-420.
32. Dewey KG, Romero-Abal ME, Quan De Serrano J, Bulux J, Peerson JM, Eagle P, Solomons NW: Effects of discontinuing coffee intake on iron status of iron-deficient Guatemalan toddlers: a randomized intervention study. Am J Clin Nutr 1997, 66:168-176.

33. Mehta SW, Pritchard ME, Stegman C: Contribution of coffee and tea to anemia among NHANES II participants. Nutr Res 1992, 12:209-222.

34. Wilkening S, Chen B, Bermejo JL, Canzian F: Is there still a need for candidate gene approaches in the era of genome-wide association studies? Genomics 2009, 93:415-419.

35. Madamanchi NR, Runge MS: Mitochondrial dysfunction in atherosclerosis. Circ Res 2007, 100:460-473.

36. Gusdon AM, Votyakova TV, Mathews CE: $m t-N d 2^{a}$ suppresses reactive oxygen species production by mitochondrial complexes I and III. J Biol Chem 2008, 83:10690-10697.

37. Stadtman ER, Moskovitz J, Berlett BS, Levine RL: Cyclic oxidation and reduction or protein methionine residues is an important antioxidant mechanism. Mol Cell Biochem 2003, 5:577-582

38. Ishizaka Y, Yamakado M, Toda A, Tani M, Ishizaka N: Relationship between coffee consumption, oxidant status, and antioxidant potential in the Japanese general population. Clin Chem Lab Med 2013, 51:1951-1959.

39. Cui X, Liu F, Wang JQ, Zhang WJ, Wang JY, Liu K, Cui SY, Zhang J, Xu RR Complete sequence analysis of mitochondrial DNA of aplastic anemia patients. Genet Mol Res 2012, 11:2130-2137.

40. Faul F, Erdfelder E, Lang AG, Buchner A: G*Power 3: a flexible statistical power analysis program for the social, behavioral, and biomedical sciences. Behav Res Methods 2007, 39:175-191.

doi:10.1186/1880-6805-33-37

Cite this article as: Kokaze et al.: Longevity-associated mitochondrial DNA $5178 \mathrm{C} / \mathrm{A}$ polymorphism modulates the effects of coffee consumption on erythrocytic parameters in Japanese men: an exploratory cross-sectional analysis. Journal of Physiological Anthropology 2014 33:37.

\section{Submit your next manuscript to BioMed Central and take full advantage of:}

- Convenient online submission

- Thorough peer review

- No space constraints or color figure charges

- Immediate publication on acceptance

- Inclusion in PubMed, CAS, Scopus and Google Scholar

- Research which is freely available for redistribution 